\title{
The clinical efficacy of lavender oil inhalation on intensity of menstrual pain from primary dysmenorrhea
}

\author{
Farid Zayeri $^{1}{ }^{\mathbb{1}}$, Ziba Raisi Dehkordi $^{2}$, Fatemeh Sadat Hosseini-Baharanchi ${ }^{3^{*}}$ \\ ${ }^{1}$ Proteomics Research Center, Department of Biostatistics, Faculty of Paramedical Sciences, Shahid Beheshti University of Medical Sciences, Tehran, \\ Iran \\ ${ }^{2}$ Department of Midwifery, School of Nursing and Midwifery, Shahrekord University of Medical Sciences, Shahrekord, Iran \\ ${ }^{3}$ Minimally Invasive Surgery Research Center, Department of Biostatistics, School of Public Health, Iran University of Medical Sciences, Tehran, Iran
}

\section{A R T I C L E I N F O}

Article Type:

Original Article

\section{Article History:}

Received: 18 February 2018

Accepted: 14 April 2019

\section{Keywords:}

Lavandula

Inhalation

Essential oil

Dysmenorrhea

\begin{abstract}
A B S T R A C T
Introduction: Primary dysmenorrhea is defined as painful menses with cramping sensation in the lower abdomen with normal ovulatory cycles which has no pelvic pathology. This study aimed to evaluate the effect of inhalation of Lavandula angustifolia (lavender) essential oil on alleviating primary dysmenorrhea.

Methods: This randomized double-blinded clinical trial included 96 students (48 in lavender and 48 in placebo groups) from Tehran University of Medical Sciences, Tehran, Iran. Single students with regular menstrual cycles suffering from primary dysmenorrhea regarding the verbal multi-dimensional scoring system were included. The intervention group was administered to inhale lavender essential oil (diluted in sesame oil in 2:1 ratio). The control group only inhaled sesame essential oil. The visual analogue scale (VAS) was used to assess the pain score at the baseline and 1,2, 4, and 48 hours after intervention. Generalized estimation equations method was used for data analysis.

Results: The students' mean \pm standard deviation (SD) age was $20.32 \pm 1.38$ years. No significant difference was found in demographic and menstrual characteristics between groups. The mean VAS was not significantly different between groups at the baseline. Lavender inhalation reduced the mean \pm SD primary dysmenorrhea score of $2.92 \pm 0.2$ according to VAS significantly during 48 first hours adjusted for baseline VAS $(P<0.001)$.

Conclusion: It could be concluded that lavender inhalation can decrease primary dysmenorrhea. The observed effectiveness of lavender inhalation as an inexpensive therapy without evidence of adverse event supports the interest for potential application of this therapy.
\end{abstract}

Implication for health policy/practice/research/medical education:

This research showed that lavender inhalation can effectively decrease primary dysmenorrhea. The potential application of this therapy is of interest due to no evidence of adverse event and low cost.

Please cite this paper as: Zayeri F, Raisi Dehkordi Z, Hosseini-Baharanchi FS. The clinical efficacy of lavender oil inhalation on intensity of menstrual pain from primary dysmenorrhea. J Herbmed Pharmacol. 2019;8(3):218-223. doi: 10.15171/jhp.2019.32.

\section{Introduction}

Dysmenorrhea is the most common gynecologic disorder in women of reproductive age which is categorized into primary and secondary ones. Primary dysmenorrhea is defined as painful menses with cramping sensation in the lower abdomen with normal ovulatory cycles every month during the reproductive years with menses in the absence of identifiable pelvic pathology (1). Dysmenorrhea accompanies spasmodic cramping pain in the inferior quadrants of the abdomen which radiates to the inner thigh (2). It usually begins a few hours before menstruation or contemporaneously at the beginning and lasts for 2-3 days (3). Dysmenorrhea symptoms usually start 6-12 months after menarche (4). Dysmenorrhea prevalence reaches its peak in the late teens or early twenties (5). Dysmenorrhea prevalence is nearly reported in $3 / 4$ of women (6). In addition, dysmenorrhea rate varies between $45 \%$ to $95 \%$ in menstruating women (7). The prevalence of dysmenorrhea among the students is $84 \%$ in Turkey (8) and $73.2 \%$ in $15-18$ years old Iranian female subjects, of whom 15\% missed school 1-7 days (9). Dysmenorrhea has a negative impact on female's quality of 
life including activity limitation and absence from school (7). In a study, sixty percent of the Canadian women experienced primary dysmenorrhea of whom $51 \%$ had limited activities and $17 \%$ reported to miss school or work (10).

There are several treatments to relieve primary dysmenorrhea such as consumption of non-steroidal antiinflammatory drugs (NSAIDs) and oral contraceptives (11). The low level of female satisfaction is reported for NSAIDs due to a failure rate of $20-25 \%$ and non-tolerable side effects (12) addition to increase in cardiovascular disease risks (13).

In addition, complementary and alternative medicine for dysmenorrhea including herbal supplements, exercise, acupuncture, acupressure, spinal manipulation, and aromatherapy have been utilized for dysmenorrhea (1417). Aromatherapy, the therapeutic use of plant-derived concentrated essences $(18,19)$, is commonly used in nursing practice to relieve the abdominal pains and to improve quality of life (20).

From hundreds of different lavenders, the most popular species grown for oil extraction is Lavandula angustifolia (21). Essential oils can be used in massage, bathing, and inhalation. Inhalation of essential oils stimulates olfactory receptor cells which results in sending impulses to the limbic system (22). Lavender as a sedative, anxiolytic, and mood modulator aromatherapy has major clinical benefits for the central nervous system (23). Essential oils could have relaxing and energizing effects which lead to pain treatment and palliative care development (24). It has been shown that aromatherapy is a safe and no pharmacologic treatment to relieve dysmenorrhea (25). In addition, Iranian females prefer complementary and alternative medicine to other methods for gynecological disorders treatment (26). Moreover, due to the high prevalence of dysmenorrhea, low efficacy of drugs and their side effects, this study was conducted to assess the effect of lavender inhalation as complementary medicine on primary dysmenorrhea in female students.

\section{Materials and Methods}

In this double-blinded clinical trial, 96 dormitory resistant students in Tehran University of Medical Sciences, Tehran, Iran were recruited. Single students aged from 18 to 28 years suffered from primary dysmenorrhea with score of two or three regarding Andersch \& Milsom's verbal multidimensional scoring system (27) were included. In addition, students with regular menstrual cycles, a normal sense of smell, no history of allergy to fragrances, having no history of contraceptives use were included. Students with absence of myoma, fibrocystadenoma, endometriosis, chronic pelvic inflammatory disease, obstructive vaginal or uterine congenital anomalies, ovarian cysts, chronic pelvic pain, metrorrhagia, systemic disease (irritable bowel syndrome, inflammatory bowel disease), and adenomyosis were qualified to recruit. Students who used analgesics to overcome dysmenorrhea or claimed having allergy to lavender were excluded. The students with primary dysmenorrhea; mild and moderate dysmenorrhea were recruited. Mild dysmenorrhea was considered as a painful menstruation that rarely inhibited the woman's normal activity, however it was sometimes necessary to take analgesics. In moderate dysmenorrhea, daily activities are affected and analgesics are needed, however work or school is usually not missed (27). The students were followed for two menses as the baseline to detect primary dysmenorrhea.

Barij Essence Pharmaceutical Company (Kashan, Iran) provided the drug which was lavender aroma diluted in sesame oil with a ratio of 2:1. The placebo was only sesame oil. Students were randomly assigned into either placebo or lavender for two consecutive cycles. The students were instructed to strew 3 drops of the essential oil or placebo on their palms and inhale it for 5 minutes at the distance of 7-10 cm from nose at the start of dysmenorrhea and every six hours until three days.

Details about sample size determination, randomization, and blinding can be found in (28). Demographic characteristics and menstrual characteristics were obtained. The pain level was assessed by visual analogue scale (VAS) ranges from 0 (no pain) to 10 (severe) (29) at baseline (1 hour before treatment), 1, 2, 4, and 48 hours.

The qualitative and quantitative variables described through frequency tables and mean and standard deviation (SD), respectively. Independent sample $t$ test and chi-square tests were utilized. Due to the repeated and correlated nature of VAS measures, generalized estimating equation (GEE) method was used to assess the effect of lavender on VAS. Data were analyzed using SPSS 16. $P$ value less than 0.05 was considered statistically significant.

\section{Results}

Ninety-six students who met the inclusion criteria were recruited the study: 48 in placebo and 48 in lavender groups. Consort diagram is shown in Figure 1. The student's mean \pm SD age was $20.32 \pm 1.38$ years. No significant difference was found in demographic and menstrual characteristics between groups (Table 1).

Figure 2 shows that the mean VAS in lavender group is noticeably lower than the placebo group in both cycles. Table 2 shows that in cycle one, the mean VAS was not different significantly between groups at the baseline $(P=0.06)$, however in cycle two, the baseline VAS was significantly lower in the lavender group $(P=0.024)$. For other time points in both cycles, the VAS mean in the lavender group was significantly lower than the placebo group $(P<0.001)$.

Table 3 shows that the students in the lavender group experienced a significantly lower VAS compared with the placebo group over time adjusted for baseline 


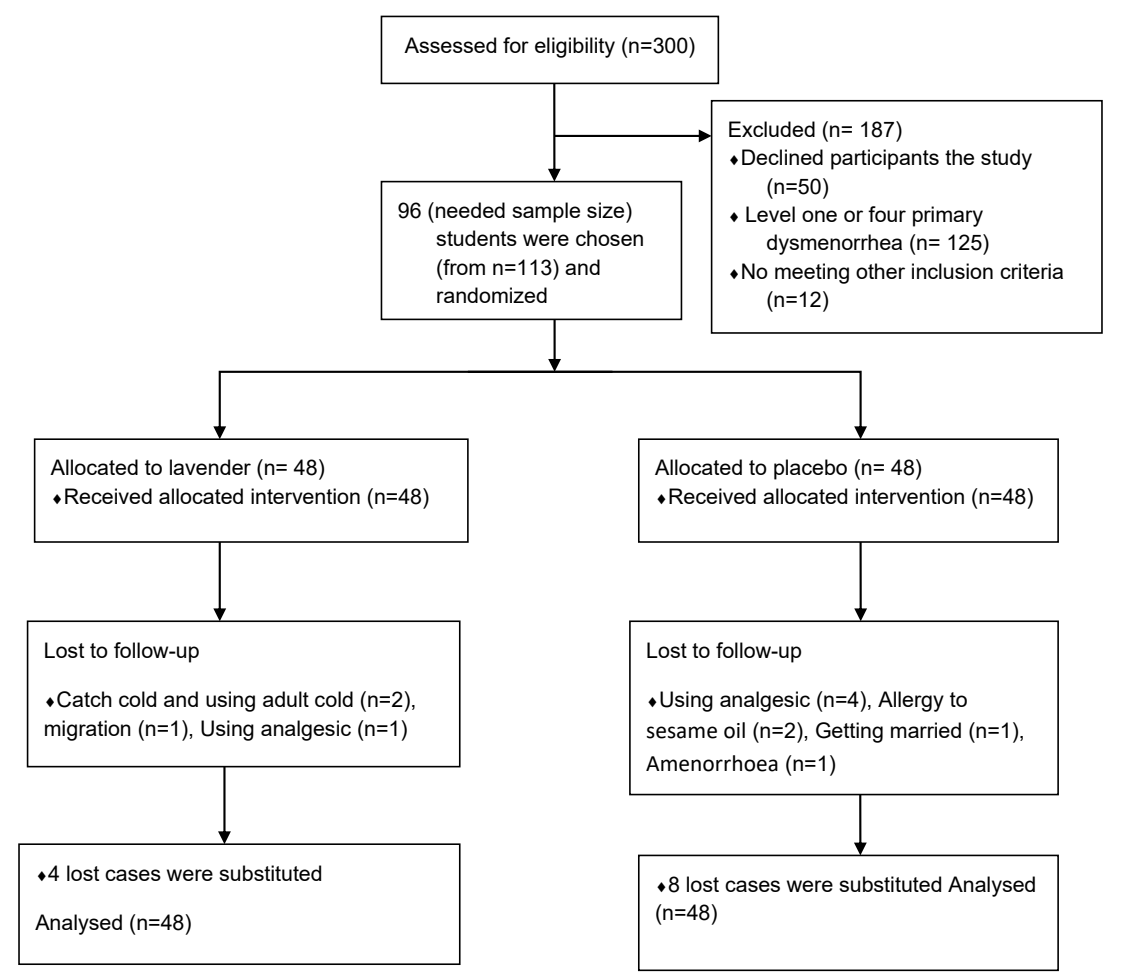

Figure 1. Consort diagram of the study.

VAS: $-2.92 \pm 0.2$ and $-2.73 \pm 0.17$ in cycles one and two, respectively $(P<0.001)$. Combining all data including cycle one and cycle two, the results revealed that the lavender inhalation reduced VAS $2.96 \pm 0.1$ units over time in comparison to the placebo group $(P<0.001)$.

\section{Discussion}

This study focused on investigating the effect of lavender inhalation on alleviating primary dysmenorrhea. It was found that lavender inhalation significantly decreased the severity of dysmenorrhea about three scores in students according to 10-point VAS. In this regards, lavender oil has also shown to decrease the severity of dysmenorrhea
(30). Inhalation of essential oils extracted from plants stimulate some olfactory receptor cells and the emotional center of the brain (31). A 10-minute lavender inhalation results in an increase in blood flow indicating a reduction in sympathetic nervous activity (32). In addition, the effect of aromatherapy using lavender essential oil on cesarean postoperative pain was studied such that the intervention group inhaled 3 drops of $10 \%$ lavender oil and the placebo group inhaled 3 drops of a base of aromatherapy blend without lavender essence for 5 minutes at the beginning of the postoperative pain, 4,8 , and 12 hours later. It was found the pain reduction after treatment use, then concluded that lavender inhalation could be as a part of

Table 1. Baseline characteristics in the lavender and the control groups

\begin{tabular}{|c|c|c|c|}
\hline Characteristic & Category & Control group & Lavender group \\
\hline \multirow{2}{*}{ Onset of dysmenorrhea } & One day before or simultaneously & $38(79.2 \%)$ & $37(77.1 \%)$ \\
\hline & Some days before & $10(20.8 \%)$ & $11(22.9 \%)$ \\
\hline \multirow{2}{*}{ Family history of dysmenorrhea } & Yes & $44(91.7 \%)$ & $42(87.5 \%)$ \\
\hline & No & $4(8.3 \%)$ & $6(12.5 \%)$ \\
\hline \multirow{3}{*}{ Frequency of painful menstruation } & Always & $15(31.2 \%)$ & $14(29.2 \%)$ \\
\hline & Most times & $29(60.4 \%)$ & $25(52.1 \%)$ \\
\hline & Sometimes & $4(8.3 \%)$ & $9(18.8 \%)$ \\
\hline Age $( \pm S D)$, year & - & $20.29( \pm 1.35)$ & $20.35( \pm 1.43)$ \\
\hline Age at menarche $( \pm S D)$, year & - & $14( \pm 1.28)$ & $13.68( \pm 1.25)$ \\
\hline Age at onset of dysmenorrhea $( \pm S D)$, year & - & $14.85( \pm 1.62)$ & $14.47( \pm 1.48)$ \\
\hline Duration between 2 menstruations ( $\pm S D$ ), day & - & $28.25(1.19)$ & $28.31(1.50)$ \\
\hline Bleeding duration $( \pm S D)$, day & - & $6.10(0.95)$ & $5.93(1.21)$ \\
\hline Pain duration $( \pm S D)$, day & - & $2.25(0.75)$ & $2.43(0.64)$ \\
\hline $\mathrm{BMI}( \pm \mathrm{SD}), \mathrm{kg} / \mathrm{m}^{2}$ & - & $21.89(3.93)$ & $20.97(2.03)$ \\
\hline
\end{tabular}



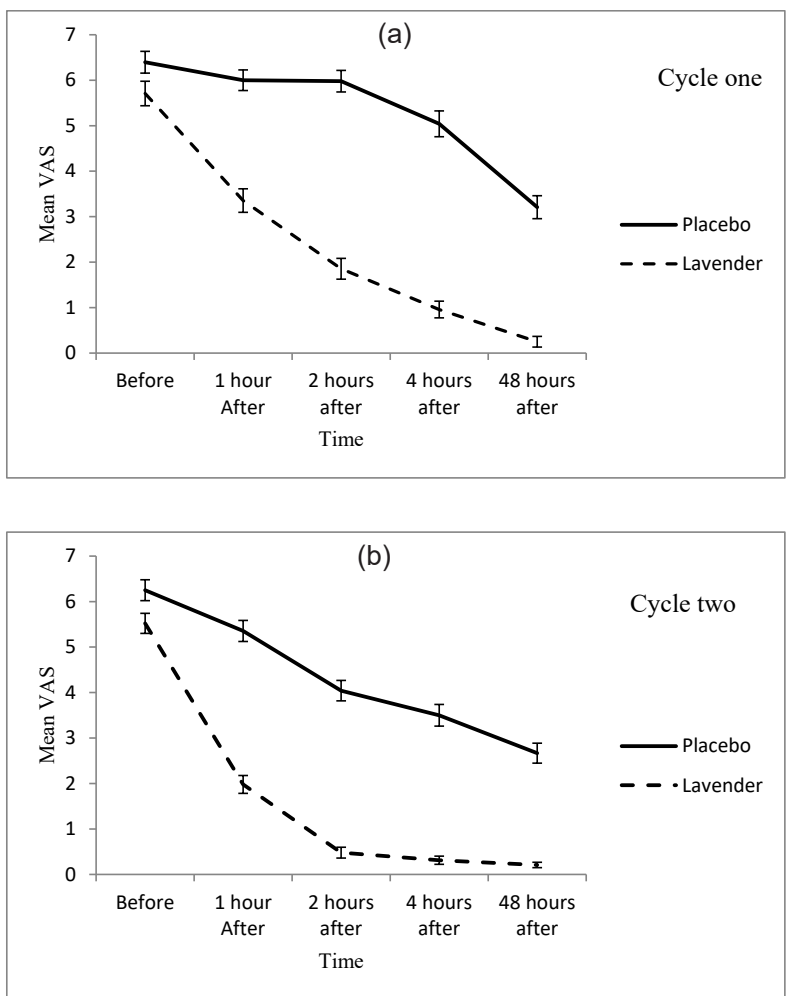

Figure 2. Error bar for VAS in lavender and placebo groups in cycle (a) one (b) two.

Table 2. Mean $\mathrm{VAS} \pm S D$ in lavender and placebo groups in all time points

\begin{tabular}{lcccc}
\hline Cycle & Time point & $\begin{array}{c}\text { Placebo group } \\
(\mathbf{n}=\mathbf{4 8})\end{array}$ & $\begin{array}{c}\text { Lavender group } \\
(\mathbf{n}=\mathbf{4 8})\end{array}$ & $\boldsymbol{P}$ \\
\hline One & Baseline & $6.39 \pm 1.65$ & $5.7 \pm 1.86$ & 0.06 \\
& $1^{\text {st }}$ hour & $6 \pm 1.57$ & $3.35 \pm 1.79$ & $<0.001$ \\
& $2^{\text {nd }}$ hour & $5.97 \pm 1.64$ & $1.85 \pm 1.58$ & $<0.001$ \\
& $4^{\text {th }}$ hour & $5.04 \pm 1.96$ & $0.95 \pm 1.27$ & $<0.001$ \\
& $48^{\text {th }}$ hour & $3.2 \pm 1.74$ & $0.25 \pm 0.81$ & $<0.001$ \\
\multirow{4}{*}{ Two } & Baseline & $6.25 \pm 1.59$ & $0.52 \pm 1.52$ & 0.024 \\
& $1^{\text {st }}$ hour & $5.35 \pm 1.6$ & $1.97 \pm 1.36$ & $<0.001$ \\
& $2^{\text {nd }}$ hour & $4.04 \pm 1.55$ & $0.47 \pm 0.82$ & $<0.001$ \\
& $4^{\text {th }}$ hour & $3.5 \pm 1.65$ & $0.31 \pm 0.62$ & $<0.001$ \\
& $48^{\text {th }}$ hour & $2.66 \pm 1.52$ & $0.2 \pm 0.41$ & $<0.001$ \\
\hline
\end{tabular}

the multidisciplinary treatment of postoperative pain (33). Barocelli et al revealed a significant effect of lavender inhalation in controlling chemical and thermal pain in animal models without any observed side effect (34).

Soltani et al showed the effect of lavender inhalation on pediatric patients aged 6-12 years who underwent tonsillectomy surgery. The patients were administered to distil 4 drops of the lavender essential oil and inhaled for 3 minutes every 6 hours. Their results demonstrated that lavender inhalation decreased the number of required analgesics following tonsillectomy (35). However, opposite results have also been found by Shahnazi et al who studied the effect of lavender aroma in intrauterine
Table 3. The effect of lavender on VAS using GEE method

\begin{tabular}{llcc}
\hline Cycle & Source of variation & Mean difference (SE) & $\boldsymbol{P}$ \\
\hline One & Group (Lavender vs control) & $-2.92(0.2)$ & $<0.001$ \\
& Time & $-0.03(0.003)$ & $<0.001$ \\
& Group* Time & $3.14(0.01)$ & $<0.001$ \\
& Baseline & $0.39(0.08)$ & $<0.001$ \\
Two & Group (Lavender vs control) & $-2.73(0.17)$ & $<0.001$ \\
& Time & $-.02(0.002)$ & $<0.001$ \\
& Group* Time & $3.8(0.014)$ & $<0.001$ \\
& Baseline & $0.44(0.06)$ & $<0.001$ \\
Total & Group (Lavender vs control) & $-2.96(0.16)$ & $<0.001$ \\
& Time & $-.0 .03(0.002)$ & $<0.001$ \\
& Group* Time & $3.75(0.12)$ & $<0.001$ \\
& Baseline & $0.43(0.07)$ & $<0.001$ \\
\hline
\end{tabular}

GEE, generalized estimating equation.

device placement pain which resulted in nonsignificant effect of lavender inhalation (36). Furthermore, Salamati et al showed no significant effect of lavender inhalation (throughout the oxygen mask) on the reduction of pain after open-heart surgery (37). These opposite findings are likely due to the differences between the mechanism of pains as well as the inhalation method.

Anti-inflammatory property of lavender might be attributed to inhibition of prostaglandin synthesis (38). Also Aromatherapy triggers the limbic system which can result in pain reduction. Furthermore, the lavender has a sedative effect that inhibits the prostanoid system involving the production of prostaglandins E2 and F2 $\alpha$ in the uterus (39). No adverse effects were observed in the present study, however, Han et al observed skin irritation in their study through lavender massage (40).

Finally, it is noteworthy that in the present randomized clinical trial also lavender inhalation relieved the severity of symptoms of dysmenorrhea such as tiredness, weakness, diarrhea, and headache. However, the amount of menstrual bleeding was not affected by lavender.

It is highly recommended to apply the numerical or verbal rating scales instead of VAS for future researches due to its difficulties in use as well as a high failure rate (41).

\section{Conclusion}

It can be concluded that the lavender inhalation is able to decrease menstrual pain according to 10 -point VAS. The observed effectiveness of lavender inhalation in primary dysmenorrhea reduction as an inexpensive therapy without evidence of adverse event supports the interest for potential application of this therapy.

\section{Authors' contributions}

FZ, ZRD and FSH contributed to the idea of the study, 
its design, analysis and interpretation. The oil extract was prepared by ZRD. However, the experimental procedures were performed by ZRD and FSH under the guidance of FZ. The manuscript was prepared, written and approved by $\mathrm{FZ}, \mathrm{ZRD}$, and $\mathrm{FSH}$.

\section{Acknowledgments}

The authors would like to appreciate Dr. Batoul Khoundabi and Dr. Neda Gilani for their corporation to enhance the quality of this article. Also the authors wish to thank the students participated in this study.

\section{Conflict of interests}

The authors declare no conflict of interest.

\section{Ethical considerations}

This study was approved by the Human Clinical Research Ethics Committee of Tehran University of Medical Sciences. The protocol was registered in Iranian Registry of Clinical Trials (IRCT) (identifier: IRCT201105086412N1). All the students signed the written informed consent. The study protocol was conformed to the ethical guidelines of the Declaration of Helsinki.

\section{Funding/Support}

None.

\section{References}

1. Vincenzo De Sanctis M, Soliman A, Bernasconi S, Bianchin L, Bona G, Bozzola M, et al. Primary dysmenorrhea in adolescents: prevalence, impact and recent knowledge. Pediatr Endocrinol Rev. 2015;13(2):512-20.

2. Wong CL. Health-related quality of life among Chinese adolescent girls with Dysmenorrhoea. Reprod health. 2018;15(1):80-90.

3. Berek JS, Novak E. Berek and Novak's gynecology: Lippincott Williams \& Wilkins; 2007.

4. Daily JW, Zhang X, Kim DS, Park S. Efficacy of ginger for alleviating the symptoms of primary dysmenorrhea: a systematic review and meta-analysis of randomized clinical trials. Pain Med. 2015;16(12):2243-55. doi: 10.1111/ pme.12853.

5. Latthe P, Mignini L, Gray R, Hills R, Khan K. Factors predisposing women to chronic pelvic pain: systematic review. BMJ. 2006;332(7544):749-55.

6. Marjoribanks J, Ayeleke RO, Farquhar C, Proctor M. Nonsteroidal anti-inflammatory drugs for dysmenorrhoea. Cochrane Database of Systematic Reviews. Cochrane Database Syst Rev. 2015;(7):CD001751. doi: 10.1002/14651858.CD001751.pub3.

7. Iacovides S, Avidon I, Baker FC. What we know about primary dysmenorrhea today: a critical review. Hum Reprod Update. 2015;21(6):762-78.

8. Aktaş D. Prevalence and factors affecting dysmenorrhea in female university students: Effect on general comfort level. Pain Manag Nurs. 2015;16(4):534-43.

9. Panahzadeh Z, Pakzad Z, Ashouri R. Survey the prevalence, knowledge and practice of guilan university students about dysmenorrhea. Journal of Guilan University of Medical Sciences. 2008; 17(66): 87-94. [Persian]

10. Burnett MA, Antao V, Black A, Feldman K, Grenville A, Lea $\mathrm{R}$, et al. Prevalence of primary dysmenorrhea in Canada. J Obstet Gynaecol Can. 2005;27(8):765.

11. Tomás-Rodríguez MI, Palazón-Bru A, John DRJM-S, Toledo-Marhuenda JV, del Rosario Asensio-García M, Gil-Guillén VF. Effectiveness of medical taping concept in primary dysmenorrhoea: a two-armed randomized trial. Sci Rep. 2015;5:16671. doi: 10.1038/srep16671.

12. Dmitrovic R, Kunselman A, Legro R. Sildenafil citrate in the treatment of pain in primary dysmenorrhea: a randomized controlled trial. Hum Reprod. 2013;28(11):2958-65. doi: 10.1093/humrep/det324.

13. De Vecchis R, Baldi C, Di Biase G, Ariano C, Cioppa C, Giasi A, et al. Cardiovascular risk associated with celecoxib or etoricoxib: a meta-analysis of randomized controlled trials which adopted comparison with placebo or naproxen. Minerva Cardioangiol. 2014;62(6):437-48.

14. Jenabi $\mathrm{E}$. The effect of ginger for relieving of primary dysmenorrhoea. J Pak Med Assoc. 2013;63(1):8-10.

15. Dehnavi ZM, Jafarnejad F, Kamali Z. The Effect of aerobic exercise on primary dysmenorrhea: A clinical trial study. J Educ Health Promot. 2018;7:3. doi: 10.4103/jehp. jehp_79_17.

16. Monji F, Hashemian F, SalehiSurmaghi MH, Mohammadyari F, Ghiyaei S, Soltanmohammadi A. Therapeutic effects of standardized formulation of Stachys lavandulifolia Vahl on primary dysmenorrhea: a randomized, doubleblind, crossover, placebo-controlled pilot study. J Altern Complement Med. 2018;24(11):1092-1098.

17. Yu S, Wen Y, Xia W, Yang M, Lv Z, Li X, et al. Acupoint herbal plaster for patients with primary dysmenorrhea: study protocol for a randomized controlled trial. Trials. 2018;19(1):348-353. doi: 10.1186/s13063-018-2682-8.

18. Ali B, Al-Wabel NA, Shams S, Ahamad A, Khan SA, Anwar F. Essential oils used in aromatherapy: A systemic review. Asian Pac J Trop Biomed. 2015;5(8):601-11.

19. Taavoni S, Darsareh F, Joolaee S, Haghani H. The effect of aromatherapy massage on the psychological symptoms of postmenopausal Iranian women. Complement Ther Med. 2013;21(3):158-63.

20. Kyle G. Evaluating the effectiveness of aromatherapy in reducing levels of anxiety in palliative care patients: results of a pilot study. Complement Ther Clin Pract. 2006;12(2):148-55.

21. Peter K. Handbook of herbs and spices. USA: CRC; 2004.

22. Dye J. Aromatherapy for women \& childbirth. Saffron Walden: The CW Daniel company. 1997.

23. Chu CJ, Kemper KJ. Lavender (Lavandula spp.). Longwood Herbal Task Force. London. 2005.

24. Barré L. Aromatherapy in nursing homes. Soins. 2014;60(797):10-2.

25. Irmak Sapmaz H, Uysal M, Taş U, Esen M, Barut M, Somuk BT, et al. The effect of lavender oil in patients with renal colic: a prospective controlled study using objective and subjective outcome measurements. J Altern Complement Med. 2015;21(10):617-22.

26. Jenabi E, Fereidoony B. Effect of Achillea millefolium on relief of primary dysmenorrhea: a double-blind randomized 
clinical trial. J Pediatr Adolesc Gynecol. 2015;28(5):402-4.

27. Andersch B, Milsom I. An epidemiologic study of young women with dysmenorrhea. Am J Obstet Gynecol. 1982;144(6):655.

28. Raisi DZ, Hosseini BF, Bekhradi R. Effect of lavender inhalation on the symptoms of primary dysmenorrhea and the amount of menstrual bleeding: A randomized clinical trial. Complement Ther Med. 2014;22(2):212-9.

29. Wyatt KM, Dimmock PW, Hayes-Gill B, Crowe J, O'Brien P. Menstrual symptometrics: a simple computer-aided method to quantify menstrual cycle disorders. Fertil Steril. 2002;78(1):96-101.

30. Bakhtshirin F, Abedi S, YusefiZoj P, Razmjooee D. The effect of aromatherapy massage with lavender oil on severity of primary dysmenorrhea in Arsanjan students. Iran J Nurs Midwifery Res. 2015;20(1):156-162.

31. Marzouk TM, El-Nemer AM, Baraka HN. The effect of aromatherapy abdominal massage on alleviating menstrual pain in nursing students: a prospective randomized crossover study. J Evid Based Complementary Altern Med. 2013; 2013(1-2):742421. doi: 10.1155/2013/742421

32. Saeki Y, Shiohara M. Physiological effects of inhaling fragnances. International Journal of Aromatherapy. 2001;11(3):118-25.

33. Olapour A, Behaeen K, Akhondzadeh R, Soltani F, al Sadat Razavi F, Bekhradi R. The effect of inhalation of aromatherapy blend containing lavender essential oil on cesarean postoperative pain. Anesth Pain Med. 2013;3(1):203-7.

34. Barocelli E, Calcina F, Chiavarini M, Impicciatore M, Bruni
R, Bianchi A, et al. Antinociceptive and gastroprotective effects of inhaled and orally administered Lavandula hybrida Reverchon "Grosso" essential oil. Life Sci. 2004;76(2):213-23.

35. Soltani R, Soheilipour S, Hajhashemi V, Asghari G, Bagheri M, Molavi M. Evaluation of the effect of aromatherapy with lavender essential oil on post-tonsillectomy pain in pediatric patients: a randomized controlled trial. Int J Pediatr Otorhinolaryngol. 2013;77(9):1579-81.

36. Shahnazi M, Nikjoo R, Yavarikia P, Mohammad-AlizadehCharandabi S. Inhaled lavender effect on anxiety and pain caused from intrauterine device insertion. J Caring Sci. 2012;1(4):255-262.

37. Salamati A, Mashouf S, Sahbaei F, Mojab F. Effects of inhalation of lavender essential oil on open-heart surgery pain. Iran J Pharm Res. 2014;13(4):1257-1262.

38. Silvia GL, Luft C, Lunardelli A, Amaral RH, Melo DA, Donadio MV, et al. Antioxidant, analgesic and antiinflammatory effects of lavender essential oil. An Acad Bras Cienc. 2015;87(2):1397-1408.

39. Balbi C, Musone R, Menditto A, Di Prisco L, Cassese E, D’Ajello $\mathrm{M}$, et al. Influence of menstrual factors and dietary habits on menstrual pain in adolescence age. Eur J Obstet Gynecol Reprod Biol. 2000;91(2):143-8.

40. Han SH, Hur MH, Buckle J, Choi J, Lee MS. Effect of aromatherapy on symptoms of dysmenorrhea in college students: A randomized placebo-controlled clinical trial. J Altern Complement Med. 2006;12(6):535-41.

41. Williamson A, Hoggart B. Pain: a review of three commonly used pain rating scales. J Clin Nurs. 2005;14(7):798-804. 